\section{Clinical Article}

Check for updates

\title{
The Clock Is Ticking - Brain Atrophy in Case of Acute Trauma?
}

\author{
Alexandrina S. Nikova (1) ', Georgios Sioutas (1) ', Konstantinos Kotopoulos (1) ', \\ Dimitar Ganchev $\mathbb{D}^{2}$, Varvara Chatzipaulou ${ }^{3}$, and Theodossios Birbilis ${ }^{1}$
}

'Department of Neurosurgery, Democritus University of Thrace, Alexandroupolis, Greece

${ }^{2}$ Department of Radiation Oncology, University Hospital "Tsaritsa Yoanna" - ISUL, Sofia, Bulgaria

${ }^{3}$ Democritus University of Thrace, Medical School, Alexandroupolis, Greece
Received: Apr 28, 2019

Revised: Sep 19, 2019

Accepted: Sep 20, 2019

Address for correspondence:

Alexandrina Nikova

Department of Neurosurgery, Democritus

University of Thrace, Dragana 68100

Alexandroupolis, Greece.

E-mail: nikovaalex@gmail.com

Copyright (c 2019 Korean Neurotraumatology Society

This is an Open Access article distributed under the terms of the Creative Commons Attribution Non-Commercial License (https:// creativecommons.org/licenses/by-nc/4.0/) which permits unrestricted non-commercial use, distribution, and reproduction in any medium, provided the original work is properly cited.

ORCID iDs

Alexandrina S. Nikova (D)

https://orcid.org/0000-0002-0800-6955

Georgios Sioutas (iD)

https://orcid.org/0000-0003-3937-4029

Konstantinos Kotopoulos (D)

https://orcid.org/0000-0002-8069-959X

Dimitar Ganchev (D)

https://orcid.org/0000-0002-7370-6616

Conflict of Interest

The authors have no financial conflicts of interests.

\begin{abstract}
Objective: Brain atrophy and brain herniation are gaining a lot of attention separately, but a limited amount of studies connected them together, and because of this, we are going to review and examine the subject in the current meta-analysis.

Methods: The authors collected data reporting brain atrophy of alcoholic and schizophrenic cause, as well as data on control patients, all of which was published on MEDLINE between 1996 and 2018. The included 11 articles were processed with a statistical program.

Results: We found that the pericerebral space is unequal among the groups, while the intracranial volume is strongly correlated to the biggest foramen of the body. The effect of this inequality, however, is expressed in emergency cases, where the patients with brain atrophy will have more time before the final stage of brain herniation.

Conclusion: The current study raises a controversial issue that requires careful investigation and high attention from the health care personnel.
\end{abstract}

Keywords: Brain herniation; Atrophy; Brain volume; Inequalities; Protection; Foramen magnum

\section{INTRODUCTION}

Atrophy is a word suggesting degeneration and decline of function, regardless if it is used for an anatomical structure or as a metaphor of the speech. It also affects the brain, disrupting its structural balance and performance. Plenty of diseases, external factors and genetic predispositions are suggested as cause of the condition.

Meanwhile, brain herniation is a fatal result after an acute increase of the intracranial pressure (ICP), more often due to traumatic brain injury (TBI) or acute brain bleed. In normal condition a person has $75 \mathrm{~mL}$ entrant cerebrospinal fluid (CSF) at every 5 seconds and 100-130 mL entrant blood flow. The $14 \%$ of the cardiac output reaches the brain. In normal conditions (no bleed, tumor or other cause of increased brain volume [BV]) a person has ICP at about 5-10 mmHg. Every cause of increased brain pressure according to the Monro-Kellie doctrine leads to compensatory mechanisms, where the entrant fluids are reduced in order to maintain normal ICP. When the extra BV extends the 100-120 mL, the compensatory mechanisms do not work, leading to increased ICP and brain herniation. 
At first sight, the aforementioned processes seem unrelated. Reviewing them, however, one understands that BV, pericerebral space (PICS) and intracranial volume (ICV) are related to brain herniation, because of their close relation and interaction. Hence, this raises a question. If these parameters are related, are they equal? And if this relation between them exists, how does this affect us? The aim of the current study is to try to answer this question.

\section{MATERIALS AND METHODS}

In order to describe the relation between atrophy and herniation, 2 independent authors collected studies reporting brain atrophy caused by alcoholic and schizophrenic factors, all of which were found on Medline, Embase, Cochraine, Willey, Google Scholar and from the references of the articles found, between 1996 and 2018. The main reason those specific entities were chosen was that atrophy in schizophrenia is considered to be regional, allowing the examination of more than one type of atrophy, and that alcohol is the most common cause of atrophy due to substance abuse.

MeSH terms used for the search were: brain atrophy, alcohol, schizophrenia, BV, ICV and foramen magnum (FM).

Two independent authors collected the studies, while a third author analyzed the data.

Inclusion criteria were: i) human studies; ii) English language studies; iii) clinical studies; and iv) articles reporting BV and ICV or ICV and Grey and white matter, all of which are reported in $\mathrm{mL}$ or $\mathrm{cm}^{3}$ and demographics of the patients.

On the other hand, exclusion criteria were: i) non-human studies; ii) non-English studies; iii) case reports; iv) comments; v) letters to editor; vi) reviews; vii) meta-analyses; viii) studies reporting only partial data of the brain capacity or brain capacity in Liters; ix) articles with no demographic data; $\mathrm{x}$ ) articles with mean age of the participants under 19 or over 60 years; and xi) other causes of brain atrophy, except of the aforementioned (FIGURE 1).

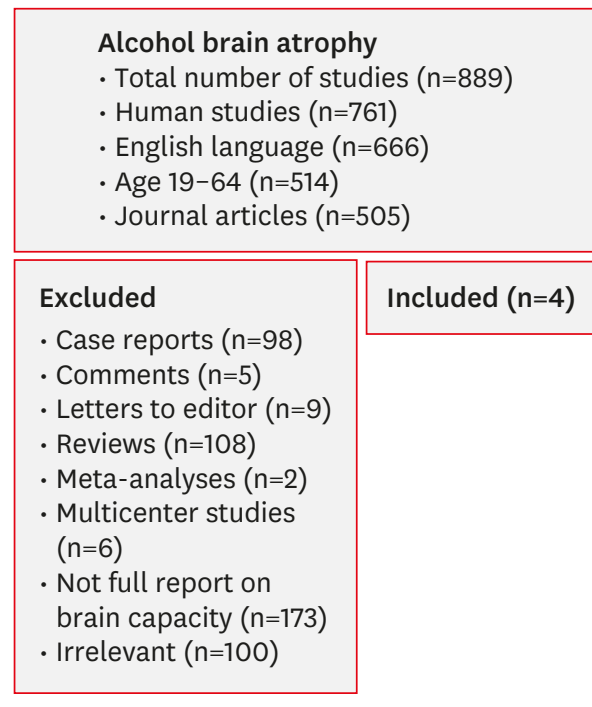

FIGURE 1. Flow chart.
Schizophrenia brain atrophy

- Total number of studies ( $n=747)$

- Human studies $(n=703)$

- English language $(n=613)$

- Age 19-64 $(n=452)$

- Journal articles $(n=434)$

$$
\begin{aligned}
& \text { Excluded } \\
& \text { - Case reports }(n=54) \\
& \text { - Comments }(n=12) \\
& \text { - Letters to editor }(n=39) \\
& \text { - Reviews }(n=74) \\
& \text { - Meta-analyses }(n=7) \\
& \text { - Multicenter studies } \\
& \text { ( } n=4) \\
& \text { - Not full report on } \\
& \text { brain capacity }(n=142) \\
& \text { - Irrelevant }(n=99)
\end{aligned}
$$


The attached studies were strictly selected based on the criteria and afterwards the data extracted from each study was divided into 3 categories - controls, alcoholic patients, and schizophrenic patients. Data collected from the studies included age, BV, ICV, FM's surface area (FMSA), and PICS.

In the case of only grey matter (GM) and white matter (WM) volume, the authors used the formula below to calculate the BV.

\section{$\mathrm{BV}=\mathrm{GM}+\mathrm{WM}$}

The PICS and FMSA were not reported, and we calculated them as it follows ${ }^{1)}$ :

$$
\begin{gathered}
\text { PICS }=\frac{\text { ICV-BV }}{\mathrm{ICV}} \text { or PICS }(\%)=\frac{\text { ICV-BV }}{\mathrm{ICV}} \times \frac{1}{100} \\
\mathrm{FMSA}=18.44+\left(0.565 \times \mathrm{ICV}\left[\mathrm{cm}^{3}\right]\right)
\end{gathered}
$$

Thereafter, the data was analyzed with Bayesian paired $t$-test and correlation analysis on Jeffreys's Amazing Statistics Program (JASP) statistical program. The Bayesian paired $t$-test is equal to the paired student $t$-test, estimating the mean of 2 groups.

\section{RESULTS}

For the final results, the authors included 11 studies with a total number of 849 patients (TABLE 1 \& FIGURE 1). 2,4-6,10,22,24,25,31,32,34) The studies were divided into 3 groups: controls, alcoholic and schizophrenic patients. The mean age of the controls, the patients with alcohol abuse, and the patients with schizophrenia were 38.61, 47.5, and 33.65, respectively.

Afterwards, Bayesian paired $t$-test was performed with Bayes factor linking to the alternative hypothesis $\left(\mathrm{BF}_{10}\right)$ (alternative hypothesis is $\left.\mathrm{A} \neq \mathrm{B}\right)$.

\begin{tabular}{|c|c|c|c|c|c|}
\hline Study & Age (year) & $\mathrm{BV}\left(\mathrm{cm}^{3}\right)$ & $\mathrm{ICV}\left(\mathrm{cm}^{3}\right)$ & PICS (\%) & Group \\
\hline Matsumae et al..$^{22)}$ & 50 & 1,227 & 1,384 & 9.39 & Controls \\
\hline \multirow[t]{2}{*}{ Reite et al. ${ }^{32)}$} & 34.34 & 1,281 & 1,413 & 9.34 & Controls \\
\hline & 39.22 & 1,260 & 1,402 & 10.13 & Schizophrenic \\
\hline Agartz et al. ${ }^{2)}$ & 47.7 & 1,228 & 1,560 & 21.12 & Alcoholic \\
\hline \multirow[t]{2}{*}{ Mechtcheriakov et al. ${ }^{24)}$} & 53.6 & 1,102 & 1,668 & 33.92 & Controls \\
\hline & & 1,005 & 1,718 & 41.47 & Alcoholic \\
\hline \multirow[t]{2}{*}{ Collin et al. ${ }^{10)}$} & 28.9 & 1,111 & 1,269 & 12.42 & Schizophrenic \\
\hline & 36.4 & 1,116 & 1,274 & 12.67 & Controls \\
\hline \multirow[t]{2}{*}{ Bjork et al. ${ }^{5)}$} & 40.1 & 1,067 & 1,353 & 21.14 & Alcoholic \\
\hline & & 1,126 & 1,377 & 18.17 & Controls \\
\hline \multirow[t]{2}{*}{ Andreone et al. ${ }^{4)}$} & 40.6 & 938 & 1,058 & 11.29 & Schizophrenic \\
\hline & 40.2 & 1,007 & 1,134 & 11.17 & Controls \\
\hline Mon et al. ${ }^{25)}$ & 50.2 & 620 & 1,488 & 58.33 & Alcoholic \\
\hline \multirow[t]{2}{*}{ Boonstra et al. ${ }^{6)}$} & 27.97 & 1,181 & 1,365 & 13.44 & Controls \\
\hline & 28.8 & 1,147 & 1,333 & 13.94 & Schizophrenic \\
\hline \multirow[t]{3}{*}{ Sullivan et al. ${ }^{34)}$} & 41.3 & 1,290 & 1,354 & 4.75 & Controls \\
\hline & 40 & 1,240 & 1,325 & 6.39 & Schizophrenic \\
\hline & 44.6 & 1,260 & 1,332 & 5.41 & Alcoholic \\
\hline \multirow[t]{2}{*}{ Rais et al. ${ }^{31)}$} & 24.39 & 1,263 & 1,518 & 16.8 & Schizophrenic \\
\hline & 23.7 & 1,327 & 1,550 & 14.39 & Controls \\
\hline
\end{tabular}

TABLE 1. List of included studies 
The results reveal very interesting facts (TABLE 2). Pericerebral space appeared to be equal among controls and schizophrenic patients, unequal between controls and alcoholic patients and unequal between schizophrenic and alcoholic patients. The Bayesian plot, FIGURE 2, shows that the alternative hypothesis (H1) or the inequality between A and B is accepted in the cases of alcoholic atrophy, while the null hypothesis (HO) is accepted only between the normal subjects and schizophrenics. The outcome suggests that the pericerebral space in the

TABLE 2. Bayesian paired $t$-test

\begin{tabular}{lcc}
\hline Groups & \multicolumn{2}{c}{ PICS } \\
\cline { 2 - 3 } & $\mathrm{BF}_{10}$ & Error (\%) \\
\hline Control vs. Schizophrenic & 1.313 & $8.164 \mathrm{e}-4$ \\
Schizophrenic vs. Alcoholic & 2.251 & 0.002 \\
Control vs. Alcoholic & 0.727 & 0.014 \\
\hline
\end{tabular}

PICS: pericerebral space, $\mathrm{BF}_{10}$ : Bayes factor.

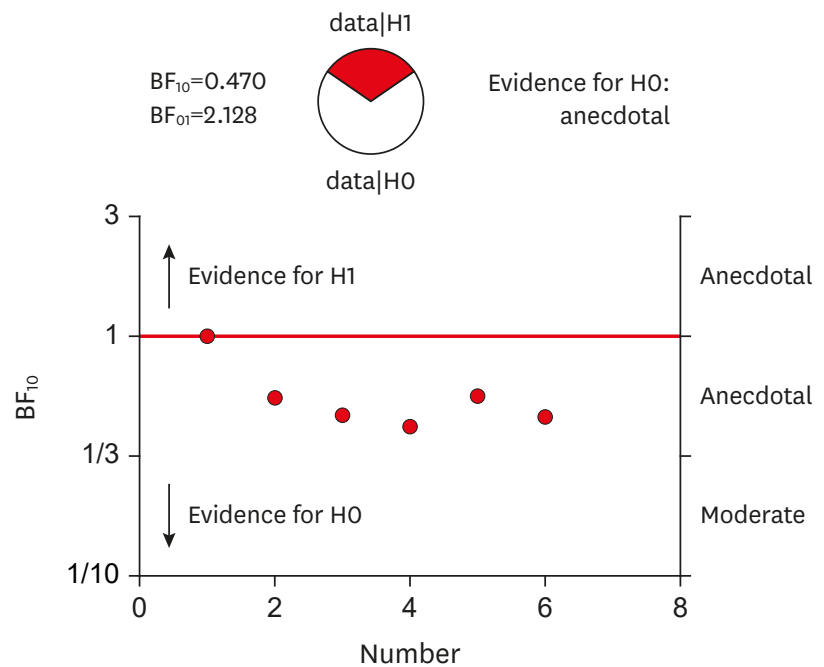

PICS controls vs. PICS schizophrenic

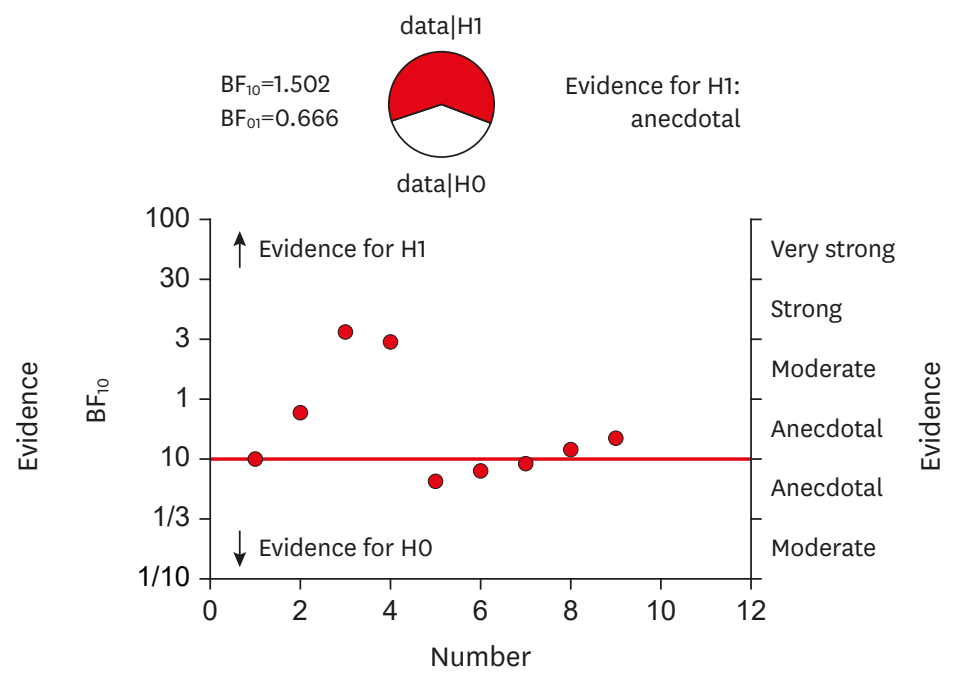

PICS controls vs. PICS alcoholics

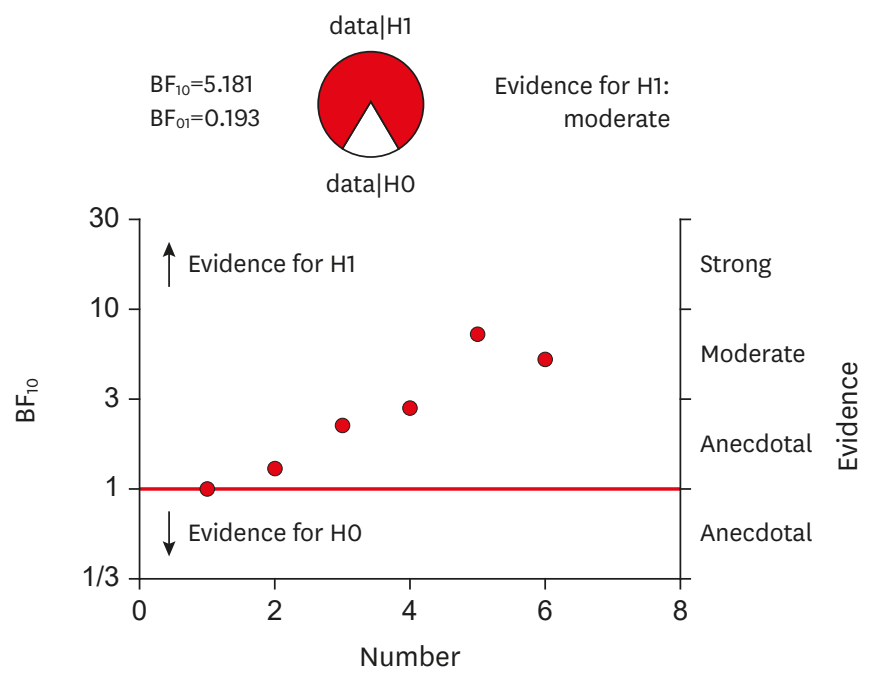

PICS alcoholic vs. PICS schizophrenic

FIGURE 2. Bayesian paired $t$-test-PICS plot.

PICS: pericerebral space, $\mathrm{BF}_{10}$ : Bayes factor. 
case of schizophrenia-related atrophy (regional) is the same as the one in normal individuals, while PICS in alcohol-related atrophy (diffuse atrophy) is unequal.

After the correlation analysis FMSA and ICV were found to be correlated with strong, positive correlation in all of the groups. (TABLES 3-5). This means that by increasing the ICV the space between the bony tissue of the FM and the nerve tissue will thicken, since the FM' opening could not grow bigger.

\begin{tabular}{|c|c|c|c|c|}
\hline Pearson correlations & PICS & Age & FM & ICV \\
\hline \multicolumn{5}{|l|}{ Age } \\
\hline Pearson's e & 0.388 & - & - & - \\
\hline$p$-value & 0.302 & - & - & - \\
\hline \multicolumn{5}{|l|}{ FM } \\
\hline Pearson's $r$ & 0.610 & 0.110 & - & - \\
\hline$p$-value & 0.081 & 0.778 & - & - \\
\hline \multicolumn{5}{|l|}{ ICV } \\
\hline Pearson's $r$ & 0.660 & 0.141 & 0.987 & - \\
\hline$p$-value & $0.053^{*}$ & 0.718 & $<0.001^{*}$ & - \\
\hline \multicolumn{5}{|l|}{ BV } \\
\hline Pearson's $r$ & -0.400 & -0.388 & 0.466 & 0.419 \\
\hline$p$-value & 0.287 & 0.302 & 0.207 & 0.262 \\
\hline
\end{tabular}

PICS: pericerebral space, FM: foramen magnum, ICV: intracranial volume, BV: brain volume.

* Significant $p$-value.

TABLE 4. Correlation matrix of alcohol atrophy

\begin{tabular}{|c|c|c|c|c|}
\hline Pearson correlations & PICS & FM & Age & ICV \\
\hline \multicolumn{5}{|l|}{$\overline{F M}$} \\
\hline Pearson's $r$ & 0.233 & - & - & - \\
\hline$p$-value & 0.490 & - & - & - \\
\hline \multicolumn{5}{|l|}{ Age } \\
\hline Pearson's $r$ & 0.443 & 0.421 & - & - \\
\hline$p$-value & 0.172 & 0.197 & - & - \\
\hline \multicolumn{5}{|l|}{ ICV } \\
\hline Pearson's $r$ & 0.239 & $1.000^{*}$ & 0.420 & - \\
\hline$p$-value & 0.479 & $<0.001^{*}$ & 0.198 & - \\
\hline \multicolumn{5}{|l|}{ BV } \\
\hline Pearson's $r$ & -0.889 & 0.233 & -0.250 & 0.228 \\
\hline$p$-value & $<0.001$ & 0.491 & 0.458 & 0.500 \\
\hline
\end{tabular}

PICS: pericerebral space, FM: foramen magnum, ICV: intracranial volume, BV: brain volume.

*Significant $p$-value.

TABLE 5. Correlation matrix of schizophrenic atrophy

\begin{tabular}{|c|c|c|c|c|}
\hline Pearson correlations & PICS & BV & ICV & Age \\
\hline \multicolumn{5}{|l|}{ FM } \\
\hline$r$ & 0.278 & 0.943 & 0.989 & -0.437 \\
\hline$p$-value & 0.594 & $0.005^{*}$ & $<0.001^{*}$ & 0.386 \\
\hline \multicolumn{5}{|l|}{ AGE } \\
\hline$r$ & -0.865 & - & - & - \\
\hline$p$-value & $0.026^{*}$ & - & - & - \\
\hline \multicolumn{5}{|l|}{ BV } \\
\hline $\mathrm{R}$ & -0.031 & - & - & -0.227 \\
\hline$p$-value & 0.953 & - & - & 0.666 \\
\hline \multicolumn{5}{|l|}{ ICV } \\
\hline $\mathrm{R}$ & 0.334 & 0.931 & - & -0.526 \\
\hline$p$-value & 0.517 & $0.007^{\star}$ & - & 0.284 \\
\hline
\end{tabular}

PICS: pericerebral space, FM: foramen magnum, ICV: intracranial volume, BV: brain volume.

*Significant $p$-value. 
No matter which group has smaller or greater volumes, the result is that there is inequality between the groups, in different analogues. Also, the FM, as an anatomical structure, has specific size, diameter and surface area. ${ }^{9,27,28)}$ In normal patient the ICV is occupied from brain tissue, blood and CSF, as the FM and has ICP between 5 and $10 \mathrm{mmHg}$.

In case of epidural/ subdural hematoma, brain trauma or other cause of increased intracranial brain pressure, according to the Monroe-Kellie dogma, CSF and blood would be first released in order ICP to be balanced. Approximately every 5 seconds the entrant CSF is $75 \mathrm{~mL}$, while the entrant blood flow 100-130 mL (1/5 arterial, 2/3 venous, and 2/3 in the microcirculation).

The mechanism of Monroe-Kellie cannot maintain normal pressure when the increase of volume extends $120-130 \mathrm{~mL}$. As a result, the ICV would increase, as well as the ICP. Since the cranium is a closed "box," except of the single opening of FM, the increase of the ICV and ICP will cause the brain to prolapse with final stage of herniation-through the FM.

In case of brain atrophy, the balance of the ICV is maintained with increased CSF, while the PICS appears bigger. Clinically, because of the differences among the PICS and BVs, and the standard size of the FM, some of those patients would have more space between the brain tissue and bone's edge, and they would theoretically develop brain herniation and probably the symptomatology of ICP and ischemia with a time-delay. Something similar is observed among elderly patients with chronic subdural hematoma, where the age-related atrophy makes space for the hematoma, and many do not show any symptoms of it, until a recurrent bleed occurs.

This states an important probability fact, requiring more investigation, but also an issue that should be considered for the first hours of management of the traumatic brain injuries and preventive measures for the general population.

\section{DISCUSSION}

The human cranial skeleton is a complex structure made up of bones and cartilages that derive from the neural crest and mesoderm. ${ }^{15)}$ It consists of 2 main parts, the neurocranium and the viscerocranium, encircling the brain, and shaping the face, respectively. As far as the neurocranium is concerned, it can be further sub classified into skull base, chondrocranium and calvaria. ${ }^{15,36)}$ According to Raam et al. ${ }^{30)}$ the adult cranial vault is made of eight separate bones. The "joints" of the cranial vault play also a major role to the separate bones of the last, holding them tight together and allowing the growth of the skull. ${ }^{15,30)}$

The skull cavity encloses brain tissue, including meninges, cerebrospinal fluid, vessels and nerves. The final size of the ICV is reached at the age of 16-20 years old and it is believed that it remains constant thereafter. ${ }^{17,37)}$ The average BV of a well-nourished European is about $1,260 \mathrm{~cm}^{3}$ for males and $1,130 \mathrm{~cm}^{3}$ for females. There are differences between the sexes due to differences in height and size..$^{3,11)}$

According to Zdilla et.al. ${ }^{38)}$ the mean FMSA is about $864 \mathrm{~mm}^{2}$. Moreover, between the FM area and dimensions there are major dissimilarities among the ethnicities and sexes. Generally, males have a considerably bigger transverse and sagittal lengths than female individuals. As a result, an important distinction is observed in the FM area between the both sexes $\left(98.78 \mathrm{~mm}^{2}\right)$, but no such distinction in the foramen's perimeters $(t=1.785)$. 
Finally, according to Acer et al. ${ }^{1)}$ the ICV's mean was estimated at $1,311 \mathrm{~cm}^{3}$. A positive association $(r=0.271, p=0.005)$ was established between ICV and FMSA. These results are the same as the ones of the current study. Furthermore, the $p$-value of this analysis is $<0.001$, while the $\mathrm{R}^{2}=1$, indicating even stronger relation between ICV and FMSA.

Atrophy, in this respect, is an end-stage status for many diseases, including substances' abuse, dementia, infections, neurological, systematic, psychiatric, and posttraumatic conditions. ${ }^{713,14,20,21,26,29,35)}$ Furthermore, there is a normal age-related loss of BV evaluated at $0.1-0.3 \%$ per year. ${ }^{12)}$ Moderate to severe brain atrophy specifically protects from the development of malignant middle cerebral artery infarction. ${ }^{23}$ This happens, because cerebral atrophy provides a compensatory intracranial space for the increase in volume and protects from regionally increase of the ICP, thus, protects patients with atrophy from herniation and death after a large cerebral infarct. ${ }^{19)}$ Apart from the general protection from fatal brain herniation in patients with intracerebral hemorrhage, brain atrophy also protects patients with basal ganglia hemorrhage, and after such, it is used as a prognostic factor for the final functional outcome..$^{16,18)}$

Brain herniation, as stated above, is a fatal condition, where the brain tissue and nerves are compressed, the vessels are obstructed and the ICP is highly increased. The management of the herniation, however, is suggested to be as rapid as possible. The recommendations ${ }^{8,33)}$ suggest that neurosurgical procedure is equal to a "gold standard." Mannitol is used in the beginning, but a quite high percentage of the individuals with severe traumatic brain injury will require surgery to prevent brain herniation. There are four types of brain herniation based on the anatomical region that is injured. Final stage, however, is the central herniation through the FM.

According to this analysis, the PICS' are different among the studied groups. The main idea is that, in case of brain injury, where the capacity of the "box" containing blood, CSF and the normal brain tissue is suppressed, the ICV could not grow independently, but a brain herniation would develop. In those cases, people with brain atrophy, because of the differences in the volumes, would have more space, thereafter a delayed fatal result. And in those cases, the "rapid management" could prevent death.

\section{CONCLUSION}

In conclusion, the study presents a theoretical suggestion that brain atrophy could be a protector of brain herniation. Since the condition itself is due to other pathological processes, it requires further investigation and high attention from the health care personnel, not only because it would require reevaluation of the brain trauma guidelines, but also different therapeutical approaches.

\section{REFERENCES}

1. Acer N, Sahin B, Ekinci N, Ergür H, Basaloglu H. Relation between intracranial volume and the surface area of the foramen magnum. J Craniofac Surg 17:326-330, 2006 PUBMED | CROSSREF 
2. Agartz I, Brag S, Franck J, Hammarberg A, Okugawa G, Svinhufvud K, et al. MR volumetry during acute alcohol withdrawal and abstinence: a descriptive study. Alcohol Alcohol 38:71-78, 2003 PUBMED | CROSSREF

3. Allen JS, Damasio H, Grabowski TJ. Normal neuroanatomical variation in the human brain: an MRIvolumetric study. Am J Phys Anthropol 118:341-358, 2002 PUBMED | CROSSREF

4. Andreone N, Tansella M, Cerini R, Rambaldelli G, Versace A, Marrella G, et al. Cerebral atrophy and white matter disruption in chronic schizophrenia. Eur Arch Psychiatry Clin Neurosci 257:3-11, 2007 PUBMED | CROSSREF

5. Bjork JM, Grant SJ, Hommer DW. Cross-sectional volumetric analysis of brain atrophy in alcohol dependence: effects of drinking history and comorbid substance use disorder. Am J Psychiatry 160:20382045, 2003 PUBMED | CROSSREF

6. Boonstra G, van Haren NE, Schnack HG, Cahn W, Burger H, Boersma M, et al. Brain volume changes after withdrawal of atypical antipsychotics in patients with first-episode schizophrenia. J Clin Psychopharmacol 31:146-153, 2011 PUBMED | CROSSREF

7. Burton EJ, McKeith IG, Burn DJ, Williams ED, O'Brien JT. Cerebral atrophy in Parkinson's disease with and without dementia: a comparison with Alzheimer's disease, dementia with Lewy bodies and controls. Brain 127:791-800, 2004 PUBMED | CROSSREF

8. Carney N, Totten AM, O'Reilly C, Ullman JS, Hawryluk GW, Bell MJ, et al. Guidelines for the Management of Severe Traumatic Brain Injury, Fourth Edition. Neurosurgery 80:6-15, 2017 PUBMED | CROSSREF

9. Chethan P, Prakash KG, Murlimanju BV, Prashanth KU, Prabhu LV, Saralaya VV, et al. Morphological analysis and morphometry of the foramen magnum: an anatomical investigation. Turk Neurosurg 22:416-419, 2012 PUBMED | CROSSREF

10. Collin G, Derks EM, van Haren NE, Schnack HG, Hulshoff Pol HE, Kahn RS, et al. Symptom dimensions are associated with progressive brain volume changes in schizophrenia. Schizophr Res 138:171-176, 2012 PUBMED | CROSSREF

11. Cosgrove KP, Mazure CM, Staley JK. Evolving knowledge of sex differences in brain structure, function, and chemistry. Biol Psychiatry 62:847-855, 2007 PUBMED | CROSSREF

12. De Stefano N, Airas L, Grigoriadis N, Mattle HP, O'Riordan J, Oreja-Guevara C, et al. Clinical relevance of brain volume measures in multiple sclerosis. CNS Drugs 28:147-156, 2014 PUBMED | CROSSREF

13. Focke NK, Kallenberg K, Mohr A, Djukic M, Nau R, Schmidt H. Distributed, limbic gray matter atrophy in patients after bacterial meningitis. AJNR Am J Neuroradiol 34:1164-1167, 2013 PUBMED | CROSSREF

14. Jáuregui-Lobera I. Neuroimaging in eating disorders. Neuropsychiatr Dis Treat 7:577-584, 2011 PUBMED | CROSSREF

15. Jin SW, Sim KB, Kim SD. Development and growth of the normal cranial vault: an embryologic review. J Korean Neurosurg Soc 59:192-196, 2016 PUBMED | CROSSREF

16. Kalita J, Misra UK, Vajpeyee A, Phadke RV, Handique A, Salwani V. Brain herniations in patients with intracerebral hemorrhage. Acta Neurol Scand 119:254-260, 2009 PUBMED | CROSSREF

17. Knutson B, Momenan R, Rawlings RR, Fong GW, Hommer D. Negative association of neuroticism with brain volume ratio in healthy humans. Biol Psychiatry 50:685-690, 2001 PUBMED | CROSSREF

18. Kwon SM, Choi KS, Yi HJ, Ko Y, Kim YS, Bak KH, et al. Impact of brain atrophy on 90-day functional outcome after moderate-volume basal ganglia hemorrhage. Sci Rep 8:4819, 2018 PUBMED | CROSSREF

19. Lee SH, Oh CW, Han JH, Kim CY, Kwon OK, Son YJ, et al. The effect of brain atrophy on outcome after a large cerebral infarction. J Neurol Neurosurg Psychiatry 81:1316-1321, 2010 PUBMED | CROSSREF

20. MacKenzie JD, Siddiqi F, Babb JS, Bagley LJ, Mannon LJ, Sinson GP, et al. Brain atrophy in mild or moderate traumatic brain injury: a longitudinal quantitative analysis. AJNR Am J Neuroradiol 23:1509-1515, 2002 PUBMED 
21. Maia da Silva MN, Millington RS, Bridge H, James-Galton M, Plant GT. Visual dysfunction in posterior cortical atrophy. Front Neurol 8:389, 2017

PUBMED | CROSSREF

22. Matsumae M, Kikinis R, Mórocz IA, Lorenzo AV, Sándor T, Albert MS, et al. Age-related changes in intracranial compartment volumes in normal adults assessed by magnetic resonance imaging. J Neurosurg 84:982-991, 1996 PUBMED | CROSSREF

23. Minnerup J, Wersching H, Ringelstein EB, Heindel W, Niederstadt T, Schilling M, et al. Prediction of malignant middle cerebral artery infarction using computed tomography-based intracranial volume reserve measurements. Stroke 42:3403-3409, 2011 PUBMED | CROSSREF

24. Mechtcheriakov S, Brenneis C, Egger K, Koppelstaetter F, Schocke M, Marksteiner J. A widespread distinct pattern of cerebral atrophy in patients with alcohol addiction revealed by voxel-based morphometry. J Neurol Neurosurg Psychiatry 78:610-614, 2007 PUBMED | CROSSREF

25. Mon A, Durazzo TC, Abe C, Gazdzinski S, Pennington D, Schmidt T, et al. Structural brain differences in alcohol-dependent individuals with and without comorbid substance dependence. Drug Alcohol Depend 144:170-177, 2014

PUBMED | CROSSREF

26. Moran C, Phan TG, Chen J, Blizzard L, Beare R, Venn A, et al. Brain atrophy in type 2 diabetes: regional distribution and influence on cognition. Diabetes Care 36:4036-4042, 2013 PUBMED | CROSSREF

27. Muthukumar N, Swaminathan R, Venkatesh G, Bhanumathy SP. A morphometric analysis of the foramen magnum region as it relates to the transcondylar approach. Acta Neurochir (Wien) 147:889-895, 2005 PUBMED | CROSSREF

28. Natsis K, Piagkou M, Skotsimara G, Piagkos G, Skandalakis P. A morphometric anatomical and comparative study of the foramen magnum region in a Greek population. Surg Radiol Anat 35:925-934, 2013 PUBMED | CROSSREF

29. Niccolini F, Politis M. Neuroimaging in Huntington's disease. World J Radiol 6:301-312, 2014 PUBMED | CROSSREF

30. Raam MS, Solomon BD, Shalev SA, Muenke M. Holoprosencephaly and craniosynostosis: a report of two siblings and review of the literature. Am J Med Genet C Semin Med Genet 154C:176-182, 2010 PUBMED | CROSSREF

31. Rais M, Cahn W, Schnack HG, Hulshoff Pol HE, Kahn RS, van Haren NE. Brain volume reductions in medication-naive patients with schizophrenia in relation to intelligence quotient. Psychol Med 42:18471856, 2012 PUBMED | CROSSREF

32. Reite M, Reite E, Collins D, Teale P, Rojas DC, Sandberg E. Brain size and brain/intracranial volume ratio in major mental illness. BMC Psychiatry 10:79, 2010 PUBMED | CROSSREF

33. Stevens RD, Huff JS, Duckworth J, Papangelou A, Weingart SD, Smith WS. Emergency neurological life support: intracranial hypertension and herniation. Neurocrit Care 17 Suppl 1:S60-S65, 2012 PUBMED | CROSSREF

34. Sullivan EV, Mathalon DH, Lim KO, Marsh L, Pfefferbaum A. Patterns of regional cortical dysmorphology distinguishing schizophrenia and chronic alcoholism. Biol Psychiatry 43:118-131, 1998 PUBMED | CROSSREF

35. Tamrazi B, Almast J. Your brain on drugs: imaging of drug-related changes in the central nervous system. Radiographics 32:701-719, 2012 PUBMED | CROSSREF

36. Tubbs RS, Bosmia AN, Cohen-Gadol AA. The human calvaria: a review of embryology, anatomy, pathology, and molecular development. Childs Nerv Syst 28:23-31, 2012 PUBMED | CROSSREF

37. Wolf H, Kruggel F, Hensel A, Wahlund LO, Arendt T, Gertz HJ. The relationship between head size and intracranial volume in elderly subjects. Brain Res 973:74-80, 2003 PUBMED | CROSSREF

38. Zdilla MJ, Russell ML, Bliss KN, Mangus KR, Koons AW. The size and shape of the foramen magnum in man. J Craniovertebr Junction Spine 8:205-221, 2017 PUBMED | CROSSREF 